\title{
Diagnostic power of scleral spur length in primary open-angle glaucoma
}

\author{
$\mathrm{Mu} \mathrm{Li}^{1,2} \cdot$ Zhaoxia Luo $^{2} \cdot$ Xiaoqin Yan ${ }^{2} \cdot$ Hong Zhang ${ }^{2}$
}

Received: 3 November 2019 / Revised: 17 February 2020 / Accepted: 24 February 2020 / Published online: 7 March 2020

(C) The Author(s) 2020

\begin{abstract}
Purpose To investigate the diagnostic capability of scleral spur length in discriminating eyes with primary open-angle glaucoma (POAG) from healthy eyes.

Methods Seventy-eight eyes of 78 patients with POAG and 93 eyes of 93 age-, sex- and axial length-matched healthy subjects were included. The scleral spur length was measured using swept-source optical coherence tomography. Receiver operating characteristic (ROC) curves were derived based on the measurements.

Results The scleral spur length was significantly shorter in POAG eyes compared with healthy eyes (Method I, $164.91 \pm 23.36$ vs. $197.60 \pm 25.32 \mu \mathrm{m}$; Method II, $145.15 \pm 16.59$ vs. $166.95 \pm 19.31 \mu \mathrm{m}$; Method III, $162.33 \pm 22.83$ vs. $185.12 \pm 23.58 \mu \mathrm{m}$, respectively; all $p<0.001$ ). The areas under ROC curves were 0.841 (Method I), 0.810 (Method II), and 0.753 (Method III) for the scleral spur length. Moreover, Schlemm's canal area was significantly associated with the scleral spur length (Method I) in both POAG $(\beta=0.027 ; p<0.001)$ and healthy $(\beta=0.016 ; p=0.009)$ groups.

Conclusions The scleral spur length had a good discriminating capability between POAG and healthy eyes, and it could be a novel biomarker for POAG evaluation clinically.
\end{abstract}

Keywords Scleral spur length $\cdot$ Schlemm's canal $\cdot$ Primary open-angle glaucoma $\cdot$ Swept-source optical coherence tomography Receiver operating characteristic curve

\section{Introduction}

Primary open-angle glaucoma (POAG) is a leading cause of irreversible blindness worldwide [1]. The most important risk factor for POAG is the elevated intraocular pressure (IOP), and the reason for that is the increase in aqueous humor outflow resistance [2-4]. Previous studies have indicated that the majority (75\%-90\%) of aqueous outflow resistance is located in the region internal to Schlemm's canal (SC), including the inner wall endothelium of SC, the basement membrane of SC, and the underlying juxtacanalicular connective tissue [5-7].

\section{Xiaoqin Yan}

yanxiaoqinyy@126.com

1 Department of Ophthalmology, Union Hospital, Tongii Medical College, Huazhong University of Science and Technology, Wuhan 430022, China

2 Department of Ophthalmology, Tongji Hospital, Tongji Medical College, Huazhong University of Science and Technology, Wuhan 430030, China
Thus, SC could be an important resistance locus in the aqueous humor outflow pathway $[8,9]$.

IOP, the autonomic nerve activity, and SC endothelial cell stiffness have been suggested to be able to affect the lumen size of SC [10-15]. Besides that, previous studies have reported that the scleral spur could also be a key factor of supporting the lumen size of SC. Via the posterior displacement of scleral spur, the force of ciliary muscle could stretch trabecular meshwork and the inner wall of SC, thus keeping SC lumen open [16-18]. When cutting the attachment between ciliary muscle and scleral spur off, the contraction of ciliary muscle induced by pilocarpine would be unable to affect the morphology of SC $[19,20]$. In addition, Nesterov et al. found that the posterior SC, where received the most force from scleral spur, is wider than the anterior SC. This result also confirmed the importance of scleral spur on the morphology of SC [21]. Thus, in consideration of the close relationship between SC and scleral spur [16-21], and the close relationship between SC and aqueous humor outflow resistance [5-9], previous studies have suggested that short scleral spur could be engaged in the pathogenesis of POAG [16, 22, 23]. 
Moreover, using different measurement methods of scleral spur length, Swain et al. have reported that the mean scleral spur length was significantly shorter in POAG eyes compared with age-matched healthy eyes, indicating that a shorter scleral spur may be a risk factor in the progression of POAG because short scleral spur would be unable to support the lumen of SC [24]. This study gave us a significant clue of the association of scleral spur length with SC and POAG. However, this study was conducted using histological slides of cadaver eye in vitro, but not in real-time and in vivo, to observe and compare the scleral spur length of POAG and age-matched healthy eyes. As a noncontact and real-time method, the newly developed swept-source optical coherence tomography (SS-OCT) has a higher scan speed and a higher axial resolution, leading to a more detailed and clear in vivo observation of anterior chamber angle biometrics, including scleral spur and SC [25]. Accordingly, this study aimed to observe and compare the scleral spur length in both POAG and healthy eyes by SS-OCT in vivo and to investigate the capability of scleral spur length in discriminating glaucomatous eyes from healthy eyes.

\section{Materials and methods}

This study was approved by the ethics committee of the Tongji Hospital, Huazhong University of Science and Technology, and adhered to the tenets of the Declaration of Helsinki. All subjects provided written informed consent prior to study participation.

\section{Subjects}

Seventy-eight glaucomatous eyes of 78 patients with POAG (nobody included and tested used pilocarpine eyedrops) and 93 healthy eyes of 93 healthy subjects were recruited. All subjects received a comprehensive ophthalmic examination, including measurement of best-corrected visual acuity, refractive error (RE) (RT-2100, NIDEK CO.LTD, Gamagori, Japan), central corneal thickness (CCT) (corneal map, SSOCT, CASIA SS-1000, Tomey Corp., Nagoya, Japan), axial length (AL) (IOL-Master, Carl Zeiss Meditec, Dublin, USA), slit-lamp examination (Haag-streit, Bern, Swiss), gonioscopy, fundus photography, IOP measurement, retinal nerve fiber layer thickness (RNFL) (spectral domain-OCT, Heidelberg Engineering $\mathrm{GmbH}$, Heidelberg, Germany), and standard automated perimetry (Humphrey Field Analyzer, Carl Zeiss Meditec, Dublin, USA). Subjects were included in the POAG group if all of the following were true: (1) at least 18 years of age, (2) a glaucomatous-appearing optic nerve (rim thinning or focal notching), (3) RNFL defect was present, (4) glaucomatous visual field defects corresponding to optic nerve changes were present, and (5) normal anterior chamber depth with an open angle. Patients who had prior ocular surgeries were excluded from participation. Patients with systemic disease (e.g., hypertension, diabetic mellitus) were also excluded. Healthy subjects were included if all of the following were true: (1) at least 18 years of age, (2) IOP of $\leq 21 \mathrm{mmHg}$ with no history of elevated IOP), (3) normal fundus, (4) no visible RNFL defect, (5) normal visual field, and (6) normal anterior chamber depth with an open angle. Potential control subjects were excluded from participation if they had a family history of glaucoma, a history of eye surgery, or systemic disease. One eye would be randomly selected from each recruited subject for SS-OCT examinations (for the measurement of scleral spur and SC).

\section{SS-OCT imaging acquisition and processing}

SS-OCT (CASIA SS-1000; Tomey Corp., Nagoya, Japan) has scan speed of 30,000 A-scans/s and an axial resolution of less than $10 \mu \mathrm{m}$. The recruited subjects were imaged with the high-density (HD) scan [25]. The participants were instructed to open the eye wide during examination, and if necessary the examiner would lightly pull the participants' upper or lower eyelid to expose the scan area adequately and avoid pressing the eye to ensure accurate measurements of SC and scleral spur. The superior, nasal, inferior, and temporal limbi were recorded separately after adjusting the fixture to the corresponding areas. The scans were performed three times and the best quality image was chosen for analysis.

\section{The measurements of scleral spur and SC parameters}

The scleral spur was a scleral protrusion at the anterior chamber angle and could be recognized in the SS-OCT image by following the boundary between the longitudinal fibers of ciliary muscle and the sclera until it reaches the anterior chamber [25]. SC was defined as a thin, black, lucent space in the HD image [26]. Optimum image contrast and magnification were subjectively defined in order to maximize the visualization of scleral spur and SC. The scleral spur length was measured in three different previously reported methods. Method I (Swain et al. [24]) (Fig. 1a): the red solid line (a curved line bisecting the width of the scleral spur at every point) represents scleral spur length, drawn from the tip of the scleral spur to the middle of the red dotted line, which connects the anterior and posterior points where the sclera curves out to form the spur (located near the posterior end of SC, to the point where the sclera begins again). Method II (Nesterov and Batmanov [21, 23, 24]) (Fig. 1b): the scleral spur length measurement (the red solid line) was taken from the tip of the scleral spur, directly to the level of the posterior end of SC. Method III (Moses and Arnzen [24, 27]) (Fig. 1c): the scleral spur length (the red solid line) was measured from the tip of the scleral spur to the level of the posterior end of SC, along 

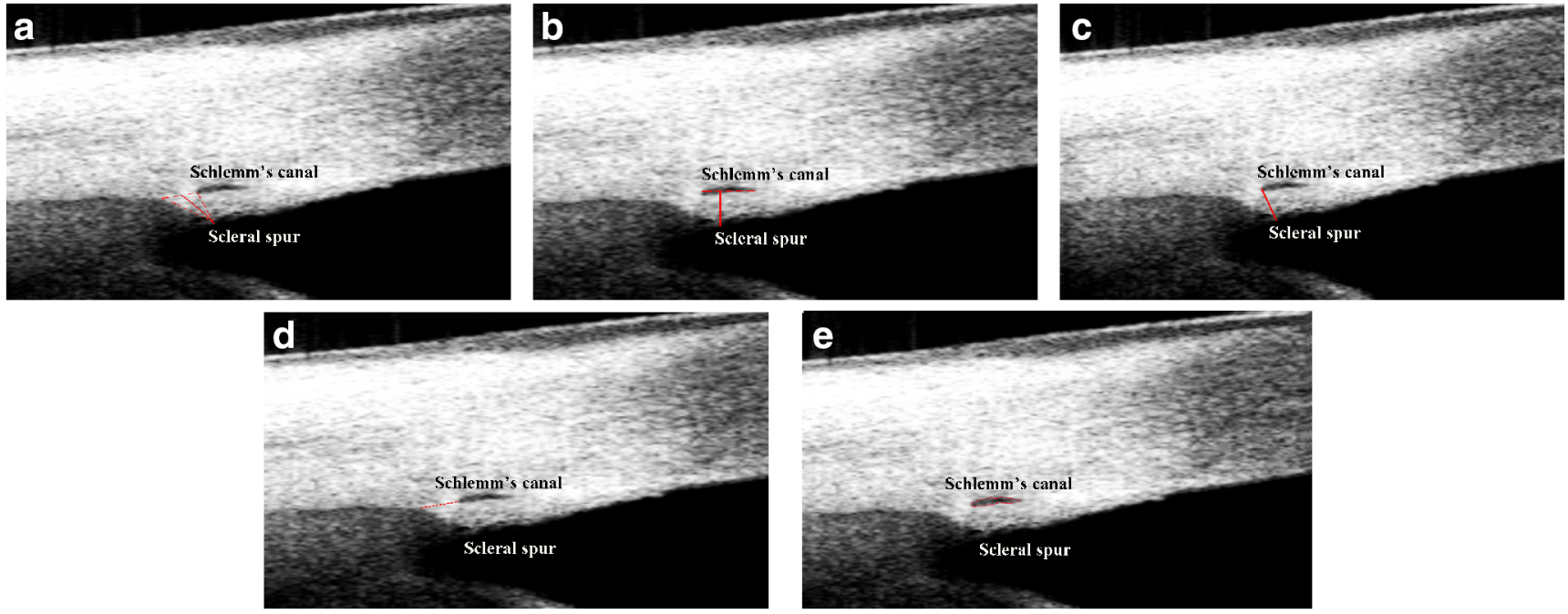

Fig. 1 The measurement of scleral spur and Schlemm's canal parameters. a The scleral spur measurement of Method I (Swain et al.): the measurement (the red solid line bisecting the width of the scleral spur at every point) was taken from the tip of the scleral spur to the middle of the red dotted line, which connects the anterior and posterior points where the sclera curves out to form the spur. b The scleral spur measurement of Method II (Nesterov and Batmanov): the measurement (the red solid line) was taken from the tip of the scleral spur, directly to the level of the

the anterior side of the scleral spur. The width of scleral spur opening was measured as the length of the red dotted line, which connects the anterior and posterior points where the sclera curves out to form the spur (Fig. 1d). The area of SC was manually drawn freehand based on the outline of SC (the red curve) (Fig. 1e). All the measurements were achieved using the ImageJ software (National Institutes of Health, Bethesda, Maryland, USA) by two separate experienced operators (ML and ZL), who were masked to the subject information. Each eye had scleral spur and SC measurements taken in the superior, nasal, inferior, and temporal quadrants and the mean scleral spur and SC parameters (the average value of superior, nasal, inferior, and temporal quadrants measurements) were chosen for further analysis.

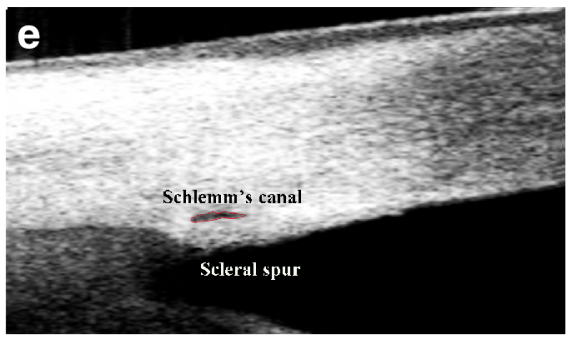

posterior end of SC. $\mathbf{c}$ The scleral spur measurement of Method III (Moses and Arnzen): the measurement (the red solid line) was taken from the tip of the scleral spur to the level of the posterior end of SC, along the anterior side of the scleral spur. $\mathbf{d}$ The measurement of scleral spur opening width: the measurement (the red dotted line) was taken from the anterior point to the posterior point where the sclera curves out to form the spur. e The area of SC (the red curve) was manually drawn freehand based on the outline of SC

\section{Statistical analysis}

All analyses were performed using $\mathrm{R}$ software version 3.4.3 (https://www.r-project.org). Data were presented as mean \pm standard deviation (SD) where applicable. Differences in continuous variables between two groups were compared using independent $t$ tests and Mann-Whitney $U$ test, while categorical the receiver operating characteristic curve (AUC) was calculated to assess the capability of each testing parameter in differentiating glaucomatous eyes from healthy eyes, where AUCs of 1 . 0 and 0.5 represent perfect and chance discrimination, respectively [28]. The univariate and multivariate regression analysis was performed to quantify the associations of scleral spur variables were compared using Chi-square test. The area under
Table 1 Demographic characteristics of study subjects

\begin{tabular}{lllr}
\hline Characteristics & POAG eyes $(n=78)$ & Healthy eyes $(n=93)$ & $p$ \\
\hline Age $($ years $)$ & $42.65 \pm 13.77$ & $40.73 \pm 12.57$ & 0.346 \\
Sex $($ male/female $)$ & $55 / 23$ & $60 / 33$ & 0.405 \\
CCT $(\mu \mathrm{m})$ & $534.71 \pm 31.64$ & $533.13 \pm 28.79$ & 0.850 \\
RE $(\mathrm{D})$ & $-2.09 \pm 2.89$ & $-1.67 \pm 2.15$ & 0.877 \\
AL $(\mathrm{mm})$ & $24.37 \pm 1.41$ & $24.17 \pm 1.25$ & 0.777 \\
IOP $(\mathrm{mmHg})$ & $22.24 \pm 7.42$ & $15.03 \pm 2.91$ & $<0.001$ \\
MD $(\mathrm{dB})$ & $-11.43 \pm 10.18$ & $-1.20 \pm 1.26$ & $<0.001$ \\
RNFL $(\mu \mathrm{m})$ & $71.38 \pm 22.31$ & $103.20 \pm 10.94$ & $<0.001$ \\
SC area $\left(\mu \mathrm{m}^{2}\right)$ & $4407.41 \pm 430.25$ & $4877.98 \pm 434.33$ & $<0.001$ \\
\hline
\end{tabular}

$P O A G$ primary open-angle glaucoma, $C C T$ central corneal thickness, $R E$ refractive error, $A L$ axial length, $I O P$ intraocular pressure, $M D$ mean deviation, $R N F L$ retinal nerve fiber thickness, $S C$ Schlemm's canal 
Table 2 Comparison of scleral spur parameters between healthy and POAG group

\begin{tabular}{llll}
\hline & POAG eyes $(n=78)$ & Healthy eyes $(n=93)$ & $p$ \\
\hline Scleral spur length $(\mu \mathrm{m}$; Method I) & $164.91 \pm 23.36$ & $197.60 \pm 25.32$ & $<0.001$ \\
Scleral spur length $(\mu \mathrm{m}$; Method II) & $145.15 \pm 16.59$ & $166.95 \pm 19.31$ & $<0.001$ \\
Scleral spur length $(\mu \mathrm{m}$; Method III) & $162.33 \pm 22.83$ & $185.12 \pm 23.58$ & $<0.001$ \\
Scleral spur opening width $(\mu \mathrm{m})$ & $135.01 \pm 42.11$ & $168.32 \pm 42.36$ & $<0.001$ \\
\hline
\end{tabular}

$P O A G$ primary open-angle glaucoma length with demographic characteristics parameters. The interobserver and intraobserver reproducibility was assessed with the intraclass correlation coefficient (ICC). All tests were twotailed and statistical significance was defined as $p$ value $<0.05$.

\section{Results}

The demographic characteristics are shown in Table 1. There were no significant differences in age, sex, central corneal thickness (CCT), refractive error (RE), and axial length (AL) between POAG and healthy eyes (all $p>0.05$ ). IOP was significantly higher $(22.24 \pm 7.42$ vs. $15.03 \pm 2.91 \mathrm{mmHg})$, and the mean deviation (MD) of visual field $(-11.43 \pm 10.18$ vs. $-1.20 \pm 1.26 \mathrm{~dB})$ and RNFL $(71.38 \pm 22.31$ vs. $103.20 \pm$ $10.94 \mu \mathrm{m}$ ) were significantly lower in POAG group compared with healthy group (all $p<0.001$ ). Moreover, SC area of POAG group was significantly smaller than that of healthy

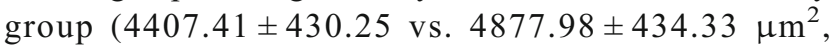
$p<0.001)$.

\section{Comparison of scleral spur parameters between POAG and healthy groups}

As Table 2 summarized, all the three measurement methods of scleral spur length showed that the scleral spur of POAG eyes was significantly shorter than that of healthy eyes $(164.91 \pm$ 23.36 vs. $197.60 \pm 25.32 \mu \mathrm{m}$ (Method I); $145.15 \pm 16.59$ vs. $166.95 \pm 19.31 \mu \mathrm{m}$ (Method II); $162.33 \pm 22.83$ vs. $185.12 \pm$ $23.58 \mu \mathrm{m}$ (Method III), all $p<0.001$ ). In addition, the scleral spur opening width was also significantly narrower in POAG eyes compared with healthy eyes $(135.01 \pm 42.11$ vs. 168.32 $\pm 42.36 \mu \mathrm{m}, p<0.001)$.


Figure 2 shows the distribution of scleral spur lengths and scleral spur opening width in both groups. The lower 90th percentile values of scleral spur lengths in healthy subjects were $167.49 \mu \mathrm{m}$ (Method I), $143.72 \mu \mathrm{m}$ (Method II), and $155.00 \mu \mathrm{m}$ (Method III), respectively. The scleral spur lengths were smaller than the lower 90th percentile values in healthy subjects in 42 (55.3\%) (Method I), 32 (41.0\%) (Method II), and 28 (35.9\%) (Method III) POAG patients, respectively. For scleral spur opening width, the lower 90th percentile value in healthy subjects was $116.42 \mu \mathrm{m}$, and the scleral spur opening width was smaller than the lower 90th percentile value in healthy subjects in $26(33.3 \%)$ POAG patients.

The AUCs of scleral spur length and scleral spur opening width to discriminate POAG subjects from healthy subjects are shown in Fig. 3 and Table 3. The areas under those curves for the scleral spur length were 0.841 (95\% confidence interval (CI) 0.780-0.902) (Method I), 0.810 (95\%CI 0.7460.875 ) (Method II), and 0.753 (95\% CI 0.681-0.825) (Method III), respectively. The area under the curve for the scleral spur opening width was 0.737 (95\%CI 0.662-0.811).

In addition, the AUC value for scleral spur length (Method I) was significantly larger than that for scleral spur length (Method III) ( $p=0.001,95 \%$ CI $0.037-0.138)$ and that for the scleral spur opening width $(p=0.033$, 95\%CI $0.008-$ 0.199) (Table 4).

\section{Univariate and multivariate regression between scleral spur length and demographic characteristic parameters}

We chose the scleral spur length measurement of Method I, which had the largest AUC, to investigate the associations of scleral spur length with demographic characteristics
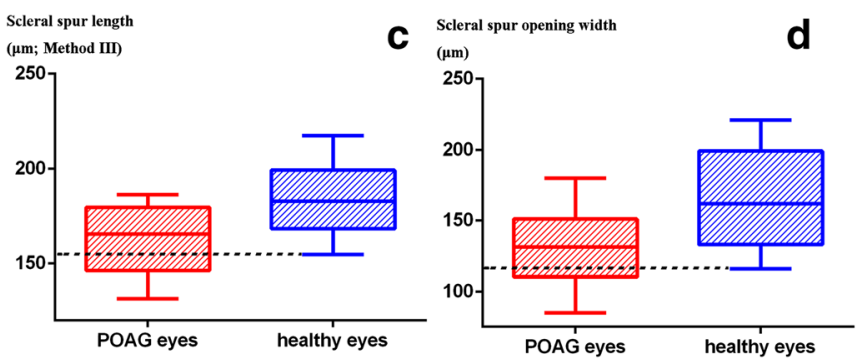

Fig. 2 Box plots showing the distributions of scleral spur lengths $(\mathbf{a}-\mathbf{c})$ and scleral spur opening width $\mathbf{d}$ in both groups. Dashed lines indicated the lower 90th percentile values in healthy subjects for scleral spur length and scleral spur opening width 
Fig. 3 Receiver operating characteristic curves for scleral spur length and scleral spur opening width

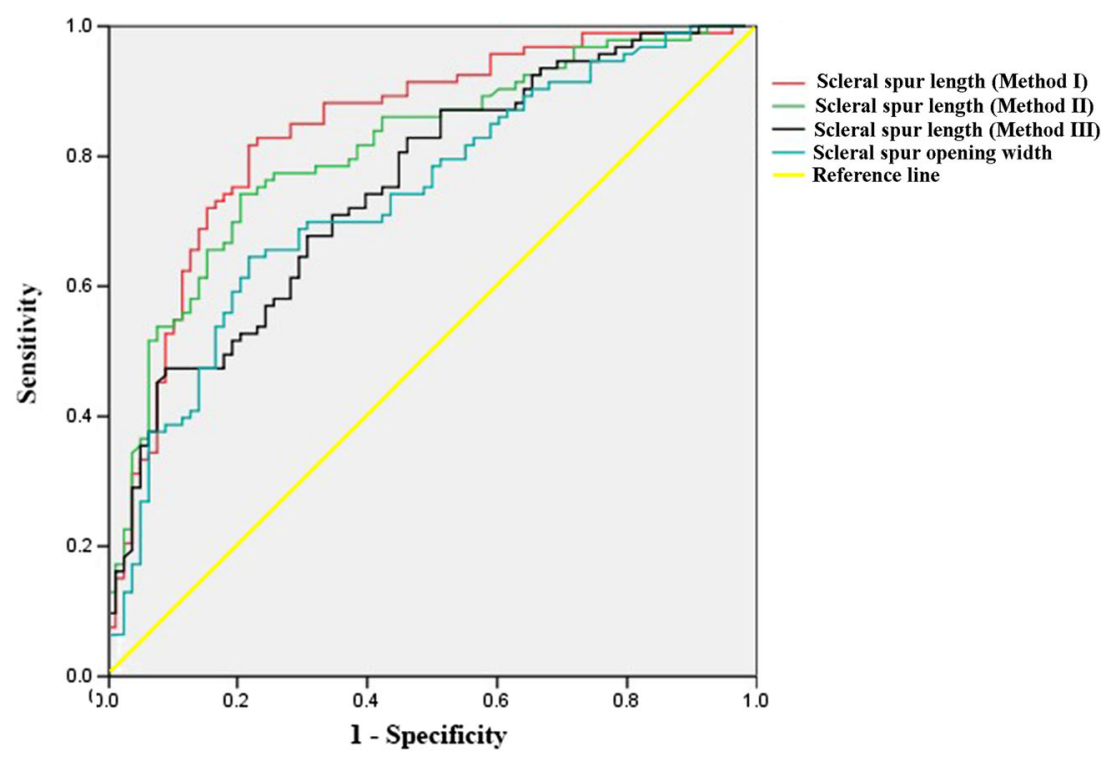

parameters. The multivariate regression results showed that in both POAG and healthy groups, the SC area was significantly associated with scleral spur length (Method I) $(\beta=0.027$ and 0.016 , respectively; $p<0.001$ and $=0.009$, respectively). Besides that, no significant associations between scleral spur length (Method I) and age, sex, CCT, AL, RE, and IOP were found (all $p>0.05$ ) (Table 5).

\section{Interobserver and intraobserver reproducibility of scleral spur and SC parameter measurements}

The results of Table 6 showed that the interobserver and intraobserver reproducibility of this study was good. The ICC values of the measurements were at the range from 0.857 to 0.931 (interobserver) and from 0.868 to 0.940 (intraobserver).

\section{Discussion}

In this study, using SS-OCT, we investigated the scleral spur length in both POAG and healthy eyes and found that the scleral spur length of POAG eyes was significantly shorter than that of healthy eyes. The scleral spur length also showed a good diagnostic capability in discriminating POAG eyes from healthy eyes. Moreover, the SC area was significantly associated with the scleral spur length in both POAG and healthy groups.

The scleral spur is a wedge-shaped circular ridge protruding out of the inner sclera, from the corneoscleral portion of trabecular meshwork to the longitudinal fibers of the ciliary muscle [18]. The scleral spur contains circumferentially oriented elastic and collagenous fibers and spindle-shaped, circularly oriented contractile myofibroblast cells (scleral spur cells) [29, 30]. Among the fibers, the elastic fibers of the scleral spur are continuous posteriorly with the elastic fiber tendons of the longitudinal fibers of ciliary muscle and anteriorly with the elastic fibers in TM, along with the juxtacanalicular tissue underneath the SC inner wall endothelium $[18,29]$. Thus, the scleral spur has long been supposed to be a supporting tissue for SC and has an impact on the aqueous humor outflow facility [24]. The posterior displacement of the scleral spur could transmit the force of ciliary body to the trabecular meshwork and SC, stretch them, and keep them open [16-18]. Using immersion-fixed enucleated eye tissue by histological method, the study of Swain et al. reported that the scleral spur of POAG eyes was significantly shorter than that of healthy eyes and the shorter scleral spur length could not provide required support for the patency of SC. In addition, the shorter scleral spur also has less ciliary muscle and
Table 3 Receiver operating characteristic (ROC) curves of scleral spur parameters between POAG and healthy groups

\begin{tabular}{lllllc}
\hline & AUC & $p$ & Cut-off value & Sensitivity & Specificity \\
\hline Scleral spur length $(\mu \mathrm{m}$; Method I) & 0.841 & $<0.001$ & $179.79 \mu \mathrm{m}$ & 0.782 & 0.817 \\
Scleral spur length $(\mu \mathrm{m}$; Method II) & 0.810 & $<0.001$ & $155.69 \mu \mathrm{m}$ & 0.795 & 0.742 \\
Scleral spur length $(\mu \mathrm{m}$; Method III) & 0.753 & $<0.001$ & $186.38 \mu \mathrm{m}$ & 0.910 & 0.473 \\
Scleral spur opening width $(\mu \mathrm{m})$ & 0.737 & $<0.001$ & $151.70 \mu \mathrm{m}$ & 0.782 & 0.645 \\
\hline
\end{tabular}

$A U C$ area under receiver operating characteristic curve 
Table 4 Comparison of the AUCs between scleral spur length (Method I) and scleral spur length (Method II, Method III), scleral spur opening width

\begin{tabular}{llll}
\hline & AUC & $95 \%$ CI & $p$ \\
\hline Scleral spur length $(\mu \mathrm{m}$; Method I) & 0.841 & $0.780-0.902$ & \\
Scleral spur length $(\mu \mathrm{m}$; Method II) & 0.810 & $0.746-0.875$ & $0.386^{1}$ \\
Scleral spur length $(\mu \mathrm{m}$; Method III) & 0.753 & $0.681-0.825$ & $0.001^{2}$ \\
Scleral spur opening width $(\mu \mathrm{m})$ & 0.737 & $0.662-0.811$ & $0.033^{3}$ \\
\hline
\end{tabular}

$A U C$ area under receiver operating characteristic curve, $C I$ confidence interval

${ }^{1} p$ value between scleral spur length (Method I) and scleral spur length (Method II), ${ }^{2} p$ value between scleral spur length (Method I) and scleral spur length (Method III), ${ }^{3} p$ value between scleral spur length (Method I) and scleral spur opening width

trabecular meshwork attachment than normal eyes. When the ciliary muscle contracts and pulls the scleral spur of POAG eyes, it moves only a shorter distance posteriorly, opening fewer layer of meshwork beams and failing to support SC lumen. Thus, the shorter scleral spur of POAG eyes could compromise the "ciliary muscle-scleral spur-trabecular meshwork" network, which is important in maintaining the patency of SC. Based on this, Swain et al. speculated that individuals with a shorter scleral spur may be at a greater predisposition to POAG compared with the healthy counterparts with longer scleral spur [24].

Using SS-OCT, we measured the scleral spur length in POAG and healthy groups in this study. The scleral spur was made up of fibers [29], making it little affected by the application of anti-glaucoma drugs. Thus, although most of the POAG eyes included in this study were under antiglaucoma drug treatment, the glaucomatous scleral spur length we measured here might not be affected by the antiglaucoma drug and could be relatively comparable to its treatment-naïve status, ensuring the reality and validity of glaucomatous scleral spur length measurement and excluding the confounding effect of anti-glaucoma drugs in this study. Our results of in vivo scleral spur length measurements were similar to those of Swain et al. [24], showing that the scleral spur length of POAG eyes was significantly shorter than that of healthy eyes. In addition, given that a shorter scleral spur length could be a potential pathogenesis of POAG, we also performed ROC curves analysis to investigate the diagnostic capability of scleral spur length in discriminating POAG eyes from healthy eyes. The results showed a good discriminating capability (AUC value $=0.841$ ), and it was comparable to the previously reported respective values of other diagnostic parameters for glaucoma (e.g., global peripapillary RNFL thickness has AUCs ranging from 0.87 to 0.94 [31-33] and optic nerve head has AUCs ranging from 0.77 to 0.97 [34-36]). The high AUC value of scleral spur length indicated that this parameter could be used as a novel biomarker for POAG evaluation clinically.

We have also performed multivariate regression equation to determine the association between SC area and scleral spur length, and the results showed that irrespective in POAG or in healthy group, the SC area was significantly associated with the scleral spur length; the longer scleral spur could better support SC, resulting in the larger SC area. This result confirmed the previous study conclusions, which indicated the important role of scleral spur in the patency of SC [16-18,

Table 5 Univariate and multivariate regression between scleral spur length and demographic characteristics parameters

\begin{tabular}{|c|c|c|c|c|c|c|c|c|}
\hline & \multicolumn{4}{|c|}{ Scleral spur length of POAG eyes } & \multicolumn{4}{|c|}{ Scleral spur length of healthy eyes } \\
\hline & \multicolumn{2}{|l|}{ Univariate } & \multicolumn{2}{|l|}{ Multivariate } & \multicolumn{2}{|l|}{ Univariate } & \multicolumn{2}{|l|}{ Multivariate } \\
\hline & $\beta[95 \% \mathrm{CI}]$ & $p$ & $\beta[95 \% \mathrm{CI}]$ & $p$ & $\beta[95 \% \mathrm{CI}]$ & $p$ & $\beta[95 \% \mathrm{CI}]$ & $p$ \\
\hline Age (years) & $\begin{array}{l}0.354 \\
{[-0.019,0.727]}\end{array}$ & 0.066 & $\begin{array}{l}0.010 \\
{[-0.409,0.428]}\end{array}$ & 0.963 & $\begin{array}{l}0.461 \\
{[0.059,0.864]}\end{array}$ & 0.027 & $\begin{array}{l}0.183 \\
{[-0.312,0.677}\end{array}$ & 0.471 \\
\hline Sex & $\begin{array}{l}9.798 \\
{[-1.430,21.026]}\end{array}$ & 0.091 & $\begin{array}{l}1.734 \\
{[-8.790,12.259]}\end{array}$ & 0.748 & $\begin{array}{l}5.812 \\
{[-4.936,16.560]}\end{array}$ & 0.292 & $\begin{array}{l}2.842 \\
{[-8.583,14.266]}\end{array}$ & 0.627 \\
\hline $\mathrm{CCT}(\mu \mathrm{m})$ & $\begin{array}{l}-0.075 \\
{[-0.240,0.091]}\end{array}$ & 0.379 & $\begin{array}{l}-0.054 \\
{[-0.203,0.095]}\end{array}$ & 0.476 & $\begin{array}{l}-0.001 \\
{[-0.181,0.180]}\end{array}$ & 0.994 & $\begin{array}{l}0.019 \\
{[-0.174,0.213]}\end{array}$ & 0.846 \\
\hline $\mathrm{RE}$ (D) & $\begin{array}{l}1.404 \\
{[-0.387,3.195]}\end{array}$ & 0.129 & $\begin{array}{l}1.860 \\
{[-0.929,4.649]}\end{array}$ & 0.195 & $\begin{array}{l}2.372 \\
{[-0.029,4.773]}\end{array}$ & 0.051 & $\begin{array}{l}-0.294 \\
{[-5.2364 .647]}\end{array}$ & 0.907 \\
\hline $\mathrm{AL}(\mathrm{mm})$ & $\begin{array}{l}-2.304 \\
{[-5.988,1.380]}\end{array}$ & 0.224 & $\begin{array}{l}1.027 \\
{[-4.858,6.912]}\end{array}$ & 0.733 & $\begin{array}{l}-4.896 \\
{[-8.943,-0.849]}\end{array}$ & 0.020 & $\begin{array}{l}-4.511 \\
{[-13.004,3.983]}\end{array}$ & 0.301 \\
\hline IOP (mmHg) & $\begin{array}{l}-0.134 \\
{[-0.841,0.574]}\end{array}$ & 0.712 & $\begin{array}{l}-0.025 \\
{[-0.676,0.627]}\end{array}$ & 0.941 & $\begin{array}{l}-0.089 \\
{[-1.879,1.701]}\end{array}$ & 0.923 & $\begin{array}{l}0.073 \\
{[-1.809,1.954]}\end{array}$ & 0.940 \\
\hline $\mathrm{SC}$ area $\left(\mu \mathrm{m}^{2}\right)$ & $\begin{array}{l}0.027 \\
{[0.017,0.038]}\end{array}$ & $<0.001$ & $\begin{array}{l}0.027 \\
{[0.015,0.039]}\end{array}$ & $<0.001$ & $\begin{array}{l}0.016 \\
{[0.004,0.027]}\end{array}$ & 0.008 & $\begin{array}{l}0.016 \\
{[0.004,0.028}\end{array}$ & 0.009 \\
\hline
\end{tabular}

$P O A G$ primary open-angle glaucoma, $C C T$ central corneal thickness, $R E$ refractive error, $A L$ axial length, $I O P$ intraocular pressure, $S C$ Schlemm's canal, $C I$ confidence interval 
Table 6 Interobserver and intraobserver reproducibility of scleral spur and SC parameter measurements

\begin{tabular}{|c|c|c|c|c|}
\hline \multirow[t]{2}{*}{ Interobserver } & \multirow[t]{2}{*}{$\mathrm{ICC}$} & \multirow[t]{2}{*}{ Difference } & \multicolumn{2}{|l|}{$95 \% \mathrm{CI}$} \\
\hline & & & Lower & Upper \\
\hline $\mathrm{SC}$ area $\left(\mu \mathrm{m}^{2}\right)$ & 0.857 & 26.30 & 0.812 & 0.893 \\
\hline Scleral spur length ( $\mu \mathrm{m}$; Method I) & 0.885 & 4.70 & 0.848 & 0.914 \\
\hline Scleral spur length ( $\mu \mathrm{m} ;$ Method II) & 0.922 & 0.67 & 0.896 & 0.942 \\
\hline Scleral spur length ( $\mu \mathrm{m}$; Method III) & 0.931 & 0.53 & 0.908 & 0.948 \\
\hline Scleral spur opening width $(\mu \mathrm{m})$ & 0.880 & 7.36 & 0.842 & 0.910 \\
\hline \multirow[t]{2}{*}{ Intraobserver } & \multirow[t]{2}{*}{$\mathrm{ICC}$} & \multirow[t]{2}{*}{ Difference } & $95 \% \mathrm{CI}$ & \\
\hline & & & Lower & Upper \\
\hline $\mathrm{SC}$ area $\left(\mu \mathrm{m}^{2}\right)$ & 0.879 & 73.02 & 0.840 & 0.909 \\
\hline Scleral spur length ( $\mu \mathrm{m} ;$ Method I) & 0.898 & 4.32 & 0.864 & 0.923 \\
\hline Scleral spur length ( $\mu \mathrm{m} ;$ Method II) & 0.921 & 0.89 & 0.895 & 0.941 \\
\hline Scleral spur length ( $\mu \mathrm{m}$; Method III) & 0.940 & 0.43 & 0.919 & 0.955 \\
\hline Scleral spur opening width $(\mu \mathrm{m})$ & 0.868 & 8.04 & 0.825 & 0.901 \\
\hline
\end{tabular}

$I C C$ intraclass correlation coefficient, $C I$ confidence interval, $S C$ Schlemm's canal

24]. However, no other significant associations between age, sex, AL, RE, CCT, IOP, and scleral spur length were found. The reason for the no significant association between IOP and scleral spur length could be: first, most of the study recruited POAG eyes were under anti-glaucoma drugs treatment. Thus, the posttreatment IOP was affected and controlled by drugs and might not be comparable to the actual SC and glaucoma status. Second, besides SC, which was closely associated with the scleral spur length, there were also other factors that could contribute to the glaucomatous IOP (e.g., the glaucomatous changes in biomechanics and structures of SC and trabecular meshwork, the glaucomatous changes in autoregulatory control of ocular hemodynamics, the glaucomatous changes in spontaneous brain activity) [37-40]. Thus, the glaucomatous IOP might be influenced by multiple factors and could not be solely explained by SC and scleral spur.

\section{Conclusions}

Using SS-OCT, we found that the scleral spur was significantly shorter in POAG eyes compared with healthy eyes in vivo. And the scleral spur length has a good diagnostic capability in discriminating POAG eyes from healthy eyes. Thus, the scleral spur length could be a novel biomarker for POAG evaluation clinically. Moreover, the SC area was significantly associated with the scleral spur length in both POAG and healthy groups, suggesting the important role of scleral spur in the maintenance of SC morphology.

\section{Compliance with ethical standards}

Conflict of interest The authors declare that they have no conflict of interest.

Ethical approval This study was approved by the ethics committee of Tongji Hospital and adhered to the tenets of the Declaration of Helsinki.

Informed consent Informed consent was obtained from all individuals included in this study.

Open Access This article is licensed under a Creative Commons Attribution 4.0 International License, which permits use, sharing, adaptation, distribution and reproduction in any medium or format, as long as you give appropriate credit to the original author(s) and the source, provide a link to the Creative Commons licence, and indicate if changes were made. The images or other third party material in this article are included in the article's Creative Commons licence, unless indicated otherwise in a credit line to the material. If material is not included in the article's Creative Commons licence and your intended use is not permitted by statutory regulation or exceeds the permitted use, you will need to obtain permission directly from the copyright holder. To view a copy of this licence, visit http://creativecommons.org/licenses/by/4.0/.

\section{References}

1. Tham YC, Li X, Wong TY, Quigley HA, Aung T, Cheng CY (2014) Global prevalence of glaucoma and projections of glaucoma burden through 2040: a systematic review and meta-analysis. Ophthalmology 121:2081-2090. https://doi.org/10.1016/j.ophtha.2014.05.013

2. Caprioli J, Coleman AL (2008) Intraocular pressure fluctuation a risk factor for visual field progression at low intraocular pressures in the advanced glaucoma intervention study. Ophthalmology 115: 1123-1129.e3. https://doi.org/10.1016/j.ophtha.2007.10.031

3. Johnson M (2006) What controls aqueous humour outflow resistance? Exp Eye Res 82:545-557. https://doi.org/10.1016/j.exer. 2005.10.011

4. Tamm ER, Fuchshofer R (2007) What increases outflow resistance in primary open-angle glaucoma? Surv Ophthalmol 52(Suppl 2): S101-S104. https://doi.org/10.1016/j.survophthal.2007.08.002

5. Mäepea O, Bill A (1989) The pressures in the episcleral veins, Schlemm's canal and the trabecular meshwork in monkeys: effects of changes in intraocular pressure. Exp Eye Res 49:645-663. https://doi.org/10.1016/s0014-4835(89)80060-0

6. Mäepea O, Bill A (1992) Pressures in the juxtacanalicular tissue and Schlemm's canal in monkeys. Exp Eye Res 54:879-883. https://doi.org/10.1016/0014-4835(92)90151-h

7. WM GRANT (1963) Experimental aqueous perfusion in enucleated human eyes. Arch Ophthalmol 69:783-801. https://doi.org/10. 1001/archopht.1963.00960040789022

8. Rosenquist R, Epstein D, Melamed S, Johnson M, Grant WM (1989) Outflow resistance of enucleated human eyes at two different perfusion pressures and different extents of trabeculotomy. Curr Eye Res 8:12331240. https://doi.org/10.3109/02713688909013902

9. Cha ED, Xu J, Gong L, Gong H (2016) Variations in active outflow along the trabecular outflow pathway. Exp Eye Res 146:354-360. https://doi.org/10.1016/j.exer.2016.01.008

10. Kagemann L, Wang B, Wollstein G, Ishikawa H, Nevins JE, Nadler Z, Sigal IA, Bilonick RA, Schuman JS (2014) IOP elevation reduces Schlemm's canal cross-sectional area. Invest Ophthalmol Vis Sci 55:1805-1809. https://doi.org/10.1167/iovs.13-13264 
11. Battista SA, Lu Z, Hofmann S, Freddo T, Overby DR, Gong H (2008) Reduction of the available area for aqueous humor outflow and increase in meshwork herniations into collector channels following acute IOP elevation in bovine eyes. Invest Ophthalmol Vis Sci 49:5346-5352. https://doi.org/10.1167/iovs.08-1707

12. Johnstone MA, Grant WG (1973) Pressure-dependent changes in structures of the aqueous outflow system of human and monkey eyes. Am J Ophthalmol 75:365-383. https://doi.org/10.1016/00029394(73)91145-8

13. Zhou EH, Krishnan R, Stamer WD, Perkumas KM, Rajendran K, Nabhan JF, Lu Q, Fredberg JJ, Johnson M (2012) Mechanical responsiveness of the endothelial cell of Schlemm's canal: scope, variability and its potential role in controlling aqueous humour outflow. J R Soc Interface 9:1144-1155. https://doi.org/10.1098/rsif. 2011.0733

14. Gong HY, Trinkaus-Randall V, Freddo TF (1989) Ultrastructural immunocytochemical localization of elastin in normal human trabecular meshwork. Curr Eye Res 8:1071-1082. https://doi.org/10. 3109/02713688908997400

15. Fujimoto $T$, Inoue $T$, Kameda $T$, Kasaoka N, Inoue-Mochita $M$, Tsuboi N, Tanihara H (2012) Involvement of RhoA/rhoassociated kinase signal transduction pathway in dexamethasoneinduced alterations in aqueous outflow. Invest Ophthalmol Vis Sci 53:7097-7108. https://doi.org/10.1167/iovs.12-9989

16. Moses RA, Grodzki WJ Jr (1977) The scleral spur and scleral roll. Invest Ophthalmol Vis Sci 16:925-931 https://www.ncbi.nlm.nih. gov/pubmed/908645

17. Rohen JW, Lütjen E, Bárány E (1967) The relation between the ciliary muscle and the trabecular meshwork and its importance for the effect of miotics on aqueous outflow resistance. A study in two contrasting monkey species, Macaca irus and Cercopithecus aethiops. Albrecht Von Graefes Arch Klin Exp Ophthalmol 172: 23-47. https://doi.org/10.1007/bf00577152

18. Gong H, Tripathi RC, Tripathi BJ (1996) Morphology of the aqueous outflow pathway. Microsc Res Tech 33:336-367 https://doi. org/10.1002/(SICI)1097-0029(19960301)33:4<336::AIDJEMT4>3.0.CO;2-N

19. Grierson I, Lee WR, Abraham S (1978) Effects of pilocarpine on the morphology of the human outflow apparatus. Br J Ophthalmol 62:302-313. https://doi.org/10.1136/bjo.62.5.302

20. Kaufman PL, Bárány EH (1976) Loss of acute pilocarpine effect on outflow facility following surgical disinsertion and retrodisplacement of the ciliary muscle from the scleral spur in the cynomolgus monkey. Investig Ophthalmol 15:793-807 https:// www.ncbi.nlm.nih.gov/pubmed/824222

21. Nesterov AP, Batmanov YE (1972) Study on morphology and function of the drainage area of the eye of man. Acta Ophthalmol 50: 337-350. https://doi.org/10.1111/j.1755-3768.1972.tb05956.x

22. Hamanaka T (1989) Scleral spur and ciliary muscle in man and monkey. Jpn J Ophthalmol 33:221-236 https://www.ncbi.nlm.nih. gov/pubmed/2761116

23. Nesterov AP, Hasanova NH, Batmanov YE (1974) Schlemm's canal and scleral spur in normal and glaucomatous eyes. Acta Ophthalmol 52:634-646. https://doi.org/10.1111/j.1755-3768. 1974.tb01099.x

24. Swain DL, Ho J, Lai J, Gong H (2015) Shorter scleral spur in eyes with primary open-angle glaucoma. Invest Ophthalmol Vis Sci 56: 1638-1648. https://doi.org/10.1167/iovs. 14-15593

25. McKee H, Ye C, Yu M, Liu S, Lam DS, Leung CK (2013) Anterior chamber angle imaging with swept-source optical coherence tomography: detecting the scleral spur, Schwalbe's Line, and Schlemm's Canal. J Glaucoma 22:468-472. https://doi.org/10. 1097/IJG.0b013e31824485fa

26. Usui T, Tomidokoro A, Mishima K, Mataki N, Mayama C, Honda N, Amano S, Araie M (2011) Identification of Schlemm's canal and its surrounding tissues by anterior segment fourier domain optical coherence tomography. Invest Ophthalmol Vis Sci 52:6934-6939. https://doi.org/10.1167/iovs.10-7009

27. Moses RA, Arnzen RJ (1980) The trabecular mesh: a mathematical analysis. Invest Ophthalmol Vis Sci 19:1490-1497 https://www. ncbi.nlm.nih.gov/pubmed/7440103

28. Swets JA (1988) Measuring the accuracy of diagnostic systems. Science 240:1285-1293. https://doi.org/10.1126/science.3287615

29. Tamm E, Flügel C, Stefani FH, Rohen JW (1992) Contractile cells in the human scleral spur. Exp Eye Res 54:531-543. https://doi.org/ 10.1016/0014-4835(92)90132-c

30. Lütjen-Drecoll E (1999) Functional morphology of the trabecular meshwork in primate eyes. Prog Retin Eye Res 18:91-119 https:// doi.org/10.1016/s1350-9462(98)00011-1

31. Leite MT, Rao HL, Zangwill LM, Weinreb RN, Medeiros FA (2011) Comparison of the diagnostic accuracies of the Spectralis, Cirrus, and RTVue optical coherence tomography devices in glaucoma. Ophthalmology 118:1334-1339. https://doi.org/10.1016/j. ophtha.2010.11.029

32. Leung CK, Chan WM, Yung WH, Ng AC, Woo J, Tsang MK, Tse RK (2005) Comparison of macular and peripapillary measurements for the detection of glaucoma: an optical coherence tomography study. Ophthalmology 112:391-400. https://doi.org/10.1016/j. ophtha.2004.10.020

33. Park HY, Park CK (2013) Diagnostic capability of lamina cribrosa thickness by enhanced depth imaging and factors affecting thickness in patients with glaucoma. Ophthalmology 120:745-752. https://doi.org/10.1016/j.ophtha.2012.09.051

34. Wollstein G, Ishikawa H, Wang J, Beaton SA, Schuman JS (2005) Comparison of three optical coherence tomography scanning areas for detection of glaucomatous damage. Am J Ophthalmol 139:39 43. https://doi.org/10.1016/j.ajo.2004.08.036

35. Rao HL, Zangwill LM, Weinreb RN, Sample PA, Alencar LM, Medeiros FA (2010) Comparison of different spectral domain optical coherence tomography scanning areas for glaucoma diagnosis. Ophthalmology 117:1692-1699-161699.e1. https://doi.org/10. 1016/j.ophtha.2010.01.031

36. Mwanza JC, Durbin MK, Budenz DL, Sayyad FE, Chang RT, Neelakantan A, Godfrey DG, Carter R, Crandall AS (2012) Glaucoma diagnostic accuracy of ganglion cell-inner plexiform layer thickness: comparison with nerve fiber layer and optic nerve head. Ophthalmology 119:1151-1158. https://doi.org/10.1016/j. ophtha.2011.12.014

37. Xin C, Wang RK, Song S, Shen T, Wen J, Martin E, Jiang Y, Padilla S, Johnstone M (2017) Aqueous outflow regulation: optical coherence tomography implicates pressure-dependent tissue motion. Exp Eye Res 158:171-186. https://doi.org/10.1016/j.exer.2016.06.007

38. Stamer WD, Braakman ST, Zhou EH, Ethier CR, Fredberg JJ, Overby DR, Johnson M (2015) Biomechanics of Schlemm's canal endothelium and intraocular pressure reduction. Prog Retin Eye Res 44:86-98. https://doi.org/10.1016/j.preteyeres.2014.08.002

39. Galambos P, Vafiadis J, Vilchez SE, Wagenfeld L, Matthiessen ET, Richard G, Klemm M, Zeitz O (2006) Compromised autoregulatory control of ocular hemodynamics in glaucoma patients after postural change. Ophthalmology 113(10):1832-1836. https://doi.org/10.1016/j.ophtha.2006.05.030

40. Song Y, Mu K, Wang J, Lin F, Chen Z, Yan X, Hao Y, Zhu W, Zhang H (2014) Altered spontaneous brain activity in primary open angle glaucoma: a resting-state functional magnetic resonance imaging study. PLoS One 9:e89493. https://doi.org/10.1371/journal. pone. 0089493

Publisher's note Springer Nature remains neutral with regard to jurisdictional claims in published maps and institutional affiliations. 